\title{
Open
}

Review

\section{Novel endogenous angiogenesis inhibitors and their therapeutic potential}

\author{
Nithya RAO, Yu Fei LEE, Ruowen GE*
}

Department of Biological Sciences, National University of Singapore, Singapore 117543, Singapore

\begin{abstract}
Angiogenesis, the formation of new blood vessels from the pre-existing vasculature is essential for embryonic development and tissue homeostasis. It also plays critical roles in diseases such as cancer and retinopathy. A delicate balance between pro- and anti-angiogenic factors ensures normal physiological homeostasis. Endogenous angiogenesis inhibitors are proteins or protein fragments that are formed in the body and have the ability to limit angiogenesis. Many endogenous angiogenesis inhibitors have been discovered, and the list continues to grow. Endogenous protein/peptide inhibitors are relatively less toxic, better tolerated and have a lower risk of drug resistance, which makes them attractive as drug candidates. In this review, we highlight ten novel endogenous protein angiogenesis inhibitors discovered within the last five years, including ISM1, FKBPL, CHIP, ARHGAP18, MMRN2, SOCS3, TAp73, ZNF24, GPR56 and JWA. Although some of these proteins have been well characterized for other biological functions, we focus on their new and specific roles in angiogenesis inhibition and discuss their potential for therapeutic application.
\end{abstract}

Keywords: anti-angiogenesis; endogenous angiogenesis inhibitors; ISM1; FKBPL; CHIP; ARHGAP18; MMRN2; SOCS3; TAp73; ZNF24; GPR56; JWA; cancer

Acta Pharmacologica Sinica (2015) 36: 1177-1190; doi: 10.1038/aps.2015.73; published online 21 Sep 2015

\section{Introduction}

Angiogenesis is the formation of new blood vessels from the existing vasculature. It is a tightly regulated process that is essential for embryonic development and several adult physiological processes such as wound healing and reproduction $^{[1,2]}$. Angiogenic regulation is achieved by a fine balance between stimulators and inhibitors that act together to maintain physiological homeostasis ${ }^{[3]}$. Pathological angiogenesis is a consequence of a disruption in this fine balance, resulting in diseases such as cancer, rheumatoid arthritis, and heart disease.

Angiogenesis is an important hallmark of cancer ${ }^{[4,5]}$. The angiogenic switch, a process that signifies tumor development from an avascular stage to a vascularized stage through the initiation of angiogenesis, is essential for tumors to grow beyond 1-2 $\mathrm{mm}^{3}$. Hence, angiogenesis has been actively explored as a drug target for cancer therapy. Over the years, a large number of angiogenesis inhibitors have been discovered and developed, ranging from endogenous angiogenesis inhibitors, such as proteins, protein fragments and microRNAs, to monoclonal antibodies and small molecule drugs.

\footnotetext{
* To whom correspondence should be addressed.

E-mail dbsgerw@nus.edu.sg

Received 2015-05-13 Accepted 2015-07-27
}

Many proteins have been identified as endogenous angiogenesis inhibitors including thrombospondins 1 and $2^{[6,7]}$, vasohibin $^{[8]}$, chondromodulin ${ }^{[9]}$, pigment epithelial derived factor ${ }^{[10]}$, platelet factor $4^{[11]}$, and several members of the interleukin and interferon families. In addition, several proteins harbor or generate protein fragments that are anti-angiogenic including endostatin (fragment of collagen XVIII) ${ }^{[12]}$, angiostatin (fragment of plasminogen) ${ }^{[13]}$, tumstatin (fragment of collagen IV) ${ }^{[14]}$, etc. Furthermore, a growing number of microRNAs have been identified as a new class of endogenous angiogenesis inhibitors ${ }^{[15]}$.

Endogenous angiogenesis inhibitors have continuously been discovered in recent years. The identification of novel endogenous angiogenesis inhibitors and the elucidation of their biological functions are essential for our understanding of angiogenesis homeostasis in physiology and their dysregulation in pathology. This new knowledge will help us design new and better drugs for angiogenesis-related diseases such as cancer.

In this review, we discuss ten endogenous anti-angiogenic proteins discovered within the last five years. These antiangiogenic proteins are representative but not exhaustive. The list includes isthmin1 (ISM1), FK506-binding proteinlike (FKBPL), carboxy-terminus of Hsc70 interacting protein (CHIP), Rho GTPase activating protein 18 (ARHGAP18), multimerin-2 (MMRN2), suppressor of cytokine signaling-3 
(SOCS-3), tumor protein 73-alpha (TAp73), zinc finger protein 24 (ZNF24), G-protein coupled receptor 56 (GPR56) and JWA. All of these endogenous proteins have proven anti-angiogenic functions, particularly in inhibiting pathological angiogenesis such as in cancer and retinopathy. Hence, these proteins have the potential to be developed into anti-angiogenic drugs for cancer or other diseases that involve excessive angiogenesis.

\section{Isthmin 1 (ISM1)}

Ism1 was first identified as a gene that is highly expressed in the isthmus organizer in the Xenopus midbrain-hindbrain boundary during embryonic development ${ }^{[16]}$. This secreted protein has an $\mathrm{N}$-terminus signal peptide, a centrally located thrombospondin type-1 repeat domain (TSR) and a C-terminal adhesion-associated domain in Mucin 4 (MUC4) and other proteins (AMOP) domain. Although this gene is present in all major vertebrates, its biological function was completely unknown until recently.

We identified ISM1 to be a novel endogenous angiogenesis inhibitor ${ }^{[17]}$. Recombinant ISM1 (rISM) inhibited endothelial cell (EC) capillary network formation on Matrigel largely through its C-terminal AMOP domain. In vivo, ISM1 potently inhibited vascular endothelial growth factor (VEGF)/basic fibroblast growth factor (bFGF)-induced angiogenesis in an implanted Matrigel plug. ISM1 inhibited VEGF, bFGF and serum-induced EC proliferation without affecting EC migration. Significantly, ISM1 also induced EC apoptosis in the presence of EC survival factors such as VEGF through a caspase-dependent pathway. Both stable overexpression of ISM1 in cancer cells and systemic intravenous infusion of rISM potently suppressed xenograft tumor growth and angiogenesis in mice ${ }^{[17,18]}$.

Two EC cell-surface ISM1 receptors have been identified by our lab ${ }^{[18,19]}$. While av $\beta 5$ integrin serves as a low-affinity receptor that binds ISM1 with $\mu \mathrm{M}$ affinity, cell-surface glucose regulated protein 78 (GRP78) is a high-affinity receptor that binds ISM1 in the $\mathrm{nM}$ range. We demonstrated that ISM1 exerts its anti-angiogenic effect and induces EC apoptosis through two independent signaling pathways mediated by its two cell-surface receptors (Figure 1). ISM1 induces EC apoptosis through av $\beta 5$ integrin-mediated death by direct recruitment and activation of caspase-8 without causing anoikis ${ }^{[19]}$. Further, ISM1-GRP78 interaction triggers endocytosis of this ligand-receptor complex. The internalized ISM-GRP78 complexes are targeted to the mitochondria, leading to mitochondrial dysfunction and cell death ${ }^{[18]}$.

GRP78 is a member of the HSP70 heat shock chaperon family. It is a major endoplasmic reticulum (ER) stress response protein that is overexpressed in cells under stress and protects stressed cells from cell death ${ }^{[20]}$. In normal cells, GRP78 is dominantly localized to the ER lumen. However, in stressed cells, GRP78 is overexpressed, and a portion of GRP78 is translocated to the cell surface and serves as a signaling receptor. Knockdown of GRP78 expression by siRNA or blocking of cell-surface GRP78 by anti-GRP78 antibody both disrupt the pro-apoptotic function of $\mathrm{ISM}^{[18]}$.

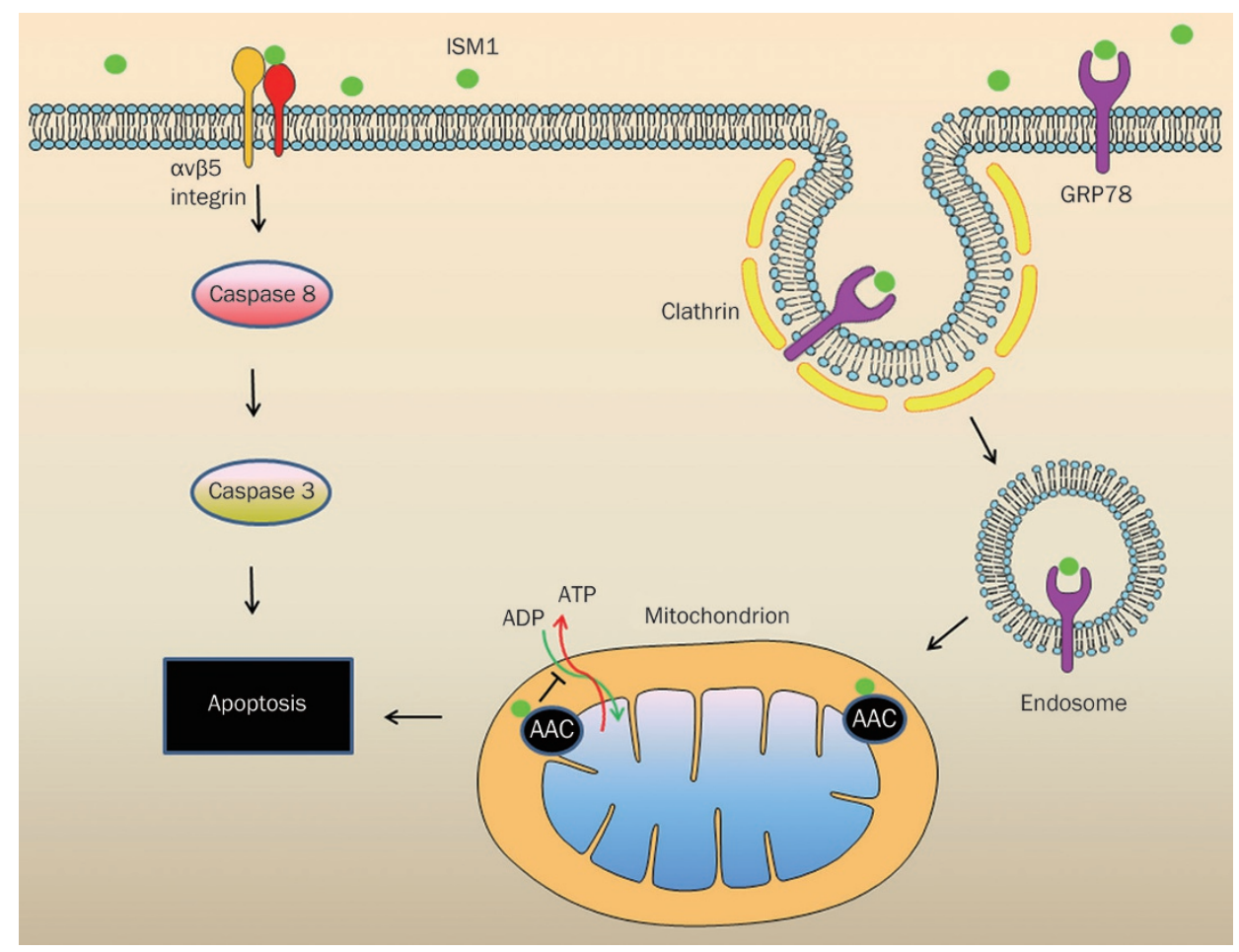

Figure 1. Mechanism of action of isthmin on endothelial cells. On the left, ISM1 binds to integrin $\alpha \mathrm{v} \beta 5$ and triggers apoptosis via the recruitment and activation of caspase-8. On the right, ISM1 binds to cell surface GRP78 and is internalized via clathrin-mediated endocytosis. ISM1-GRP78 is then trafficked to mitochondria where it binds to AAC and induces apoptosis by interfering with ADP/ATP exchange. 
Upon interaction with cell-surface GRP78, ISM1 is internalized together with GRP78 through clathrin-dependent endocytosis. Interestingly, the internalized ISM-GRP78 complex is targeted to the mitochondria. Both cell fractionation and fluorescent imaging experiments have shown the mitochondrial targeting of ISM1 via GRP78. An analysis of ISM1's interaction partners within the mitochondria revealed members of the mitochondrial ATP/ADP carriers (ATP/ADP transporter), AAC2 and AAC3. AAC, also known as adenine nucleotide translocase or ADP/ATP translocase, is the major ADP/ATP transporter located in the mitochondrial inner membrane ${ }^{[21]}$. By interacting with AACs, ISM1 interfered with ADP/ATP exchange, blocking ATP transport from mitochondria to cytosol and ADP entry into the mitochondria from the cytosol. Nevertheless, ISM does not disrupt the mitochondrial membrane potential and integrity. Consistently, no release of the mitochondrial apoptotic pathway components such as cytochrome $c$ into the cytosol was observed. These data indicate that ISM1 induces apoptosis mainly by blocking ATP/ADP exchange on the mitochondrial inner membrane ${ }^{[21]}$. The two ISM receptors, GRP78 and av $\beta 5$, thus mediate independent signaling pathways without convergence inside the cell (Figure 1).

Cell-surface GRP78 is preferentially present in cancer cells and cancer ECs; thus it is an attractive target for cancer therapy ${ }^{[22-24]}$. High levels of cell-surface GRP78 result from its overexpression, which is associated with tumor progression and metastasis. Accordingly, ISM1 selectively induces apoptosis in cancer cells and active ECs, which harbor high levels of cell-surface GRP78. In contrast, ISM1 has no effect on normal cells or benign tumor cells, which harbor little or no cell-surface GRP78 protein. Indeed, systemic delivery of rISM potently inhibited xenograft melanoma and breast cancer growth in mice ${ }^{[18]}$. Recombinant adenovirus expressing ISM1 significantly suppressed orthotropic glioma growth through intracerebral delivery ${ }^{[25]}$.

Thus, ISM, or its peptide derivatives, has the potential to be developed into anticancer drugs that target cell surface GRP78. To date, no drug that specifically targets cell surface GRP78 has been developed. Development in this direction is highly anticipated in the next few years.

\section{FK506 binding protein like (FKBPL)}

FKBPL (FK506 binding protein like) was initially discovered as DIR1 with a potential role in induced radioresistance ${ }^{[26]}$. It was later renamed FKBP-like due to its similarity to the FKBP family of heat-shock related proteins known as immunophilins. FKBPL has been implicated in cellular stress responses and control of the cell cycle $\mathrm{e}^{[27]}$. It has a C-terminally located tetratricopeptide repeat domain (TPR), which is important for its interaction with Hsp90 ${ }^{[28]}$. It has also been shown to interact with the steroid receptor family members, glucocorticoid receptors and androgen and estrogen receptors, and it plays a role in cellular signaling ${ }^{[29-31]}$.

A recent study highlighted the importance of FKBPL as a prognostic and predictive marker of breast cancer ${ }^{[31]}$. FKBPL expression correlated with overall survival and distant metastasis-free survival in breast cancer patients. It increases the sensitivity to anti-estrogens such as tamoxifen in breast cancer cells $^{[31]}$. Overexpression of Hsp90 is known to induce neovascularization in $v i v o^{[32]}$, and Hsp90 inhibitors have been shown to possess anti-angiogenic properties ${ }^{[33]}$. As an Hsp90 intracellular co-chaperone, FKBPL may be an anti-angiogenic protein.

Indeed, a recent study demonstrated that overexpression of FKBPL or treatment with recombinant FKBPL (rFKBPL) inhibited angiogenesis both in vitro and in vivo. FKBPL suppressed migration and tube formation in human microvascular endothelial cell line HMEC-1, without affecting proliferation ${ }^{[34]}$. rFKBPL also dose dependently inhibited blood vessel formation in an ex vivo rat aortic ring angiogenesis assay and in vivo subcutaneously implanted sponge angiogenesis assay ${ }^{[34]}$. The antiangiogenic domain of FKBPL was mapped to amino acids 34 to 57 at the N-terminus of the protein. This region is outside of the Hsp90 binding region suggesting an alternative target for FKBPL. CD44, the cell surface receptor for hyaluronan, was identified as the target of the anti-migration function of extracellular FKBPL. CD44 is known to play important roles in cell adhesion, migration, in vivo angiogenesis and tumor progression $^{[35,36]}$. FKBPL inhibited HMEC-1 migration via the inhibition of CD44 and its downstream target, the small GTPase Rac. Furthermore, a 24 amino acid synthetic peptide spanning the anti-angiogenic domain of FKBPL from aa34aa57, termed AD-01, functions similarly to full-length protein in inhibiting angiogenesis ${ }^{[34]}$. Direct intratumoral injection of FKBPL cDNA expression vector into DU145 prostate cancer xenografts exhibited dramatic reduction in tumor growth and angiogenesis compared to vector injected control tumors. In addition, systemic delivery of AD-01 peptide suppressed tumor growth in two different tumor models - DU145 prostate cancer and MDA-MB-231 breast cancer ${ }^{[34]}$.

Several characteristics suggest the great potential for FKBPL and its derivative, AD-01 synthetic peptide, to be developed into anticancer drugs. First, treatment with AD-01 led to potent inhibition of tumor progression in both prostate and breast cancer models with a dose as low as $0.003 \mathrm{mg} \cdot \mathrm{kg}^{-1} \cdot \mathrm{d}^{-1}$. Extensive central necrosis of the tumor core resulting in an empty core with a viable tumor rim, which is a classical presentation similar to other angiogenesis inhibitors in clinical trials, was also observed upon AD-01 treatment ${ }^{[37]}$. Second, intravital microscopy of the tumor blood vessels revealed not only decreased blood vessel numbers but also increased vessel diameter, which is suggestive of vessel normalization and is favorable for drug delivery. Third, AD-01 treatment did not affect the normal vasculature as evidenced by the lack of any inhibitory effect on the retinal vasculature. Fourth, failure of angiogenesis inhibitors is often attributed to the drastic side effects associated with their anti-proliferative effects ${ }^{[38]}$. Because FKBPL and AD-01 have no effect on EC proliferation and showed no observable cytotoxicity in mice, they appear to be attractive anti-angiogenic compounds. Fifth, FKBPL's effects are mediated by CD44 in the tumor vasculature; hence, it offers broad applicability over a wide range of solid tumors. 
Lastly, in addition to showing promise as a single agent, combination therapy with docetaxel showed significantly increased anticancer activity ${ }^{[34]}$.

\section{Carboxy-terminus of Hsc70 interacting protein (CHIP)}

CHIP (carboxy-terminus of Hsc70 interacting protein) was first discovered as a chaperone-associated ubiquitin ligase ${ }^{[39]}$. The CHIP protein has a TPR domain at its $\mathrm{N}$-terminus, through which it interacts with the molecular chaperones Hsc70, Hsp70 and Hsp90 and modulates their chaperone activity. At its carboxyl-terminus, CHIP has a U-box domain through which it acts as an E3 ubiquitin ligase, triggering proteosomal degradation of known chaperone substrates ${ }^{[40]}$. CHIP has been shown to ubiquitinate and degrade several oncogenic proteins, such as mutant p53 ${ }^{[41]}$, estrogen receptor $\mathrm{a}^{[42]}, \mathrm{c}-\mathrm{ErbB2} / \mathrm{neu}^{[43]}$, $\mathrm{Dbl}^{[44]}, \mathrm{Smad}^{[45]}$, hypoxia inducible factor $1 \mathrm{a}^{[46]}$, Runx $1^{[47]}$, Met receptor and steroid receptor coactivator-3 (SRC-3) ${ }^{[48,49]}$, which is supportive of a tumor suppressor role for the protein.

$\mathrm{CHIP}$ is a tumor suppressor for breast cancer and suppresses several oncogenic pathways. CHIP levels were negatively correlated with malignant breast tumors and survival of breast cancer patients. Interestingly, knockdown of CHIP in breast tumors resulted in increased vascularization, indicating an anti-angiogenic function for $\mathrm{CHIP}^{[49]}$. Surprisingly, $\mathrm{Xu}$ et al in 2011 reported that CHIP contributes to enhanced tumorigenesis of human glioma both in vitro and in vivo ${ }^{[50]}$. Malignant gliomas are characterized by a marked increase in blood vessel density ${ }^{[51]}$. However, the authors did not explore CHIP's role in tumor angiogenesis in glioma.

Recently, CHIP's role in inhibiting tumor angiogenesis in human gastric cancer (GC) was demonstrated ${ }^{[52]}$. Using human gastric cancer cell line BGC823, Wang et al showed that the stable overexpression of CHIP resulted in a significant reduction of microvessel density in these gastric tumors in vivo compared to vector controls. To study the specific effect on GC angiogenesis, conditioned media from stable CHIP overexpressing and knockdown BGC823 derivative cell lines were tested on human umbilical vein endothelial cells (HUVEC). Overexpression of CHIP resulted in $48 \%$ inhibition of HUVEC growth whereas CHIP knockdown caused a 1.82 fold increase in growth compared to corresponding vector controls. A marked reduction in EC tube formation upon CHIP overexpression and an increase in tube formation were observed when CHIP levels were knocked down ${ }^{[52]}$. CHIP interacts directly with p65 NF-kB via its U-box domain, causing ubiquitin-mediated proteosomal degradation of NF-KB. Consistently, NF-KB responsive genes such as interleukin-8 (IL-8), matrix metalloproteinase-2 (MMP-2) and VEGF ${ }^{[52]}$ were inhibited in GC.

IL-8 production is closely linked to increased vascularization, malignant phenotype and poor prognosis in several cancer types ${ }^{[53,54]}$. While CHIP reduced both IL- 8 mRNA and protein secretion, IL-8 rescued the inhibitory effects of CHIP on GC angiogenesis ${ }^{[52]}$. By inhibiting NF- $\mathrm{kB}$ activation, CHIP triggered a wide array of downstream genes and had a profound impact on many cellular processes, such as adhesion and inva- sion, in addition to angiogenesis. The fact that reduced CHIP levels are correlated with malignant phenotype in both GC and breast cancer supports the notion that restoration of CHIP may be a novel strategy for anti-angiogenic therapy for human cancer.

\section{Rho GTPase activating protein 18 (ARHGAP18)}

ARHGAP18 was initially identified as Mac guanosine triphosphatase activating protein (MacGAP) expressed in the human epididymis $^{[55]}$. ARHGAP18 contains the traditional RhoGAP domain in its $\mathrm{C}$-terminus and is one of the crucial factors that regulate RhoA to control cell shape, spreading and migration. It is required for remodeling the actin cytoskeleton in response to integrin engagement ${ }^{[56]}$.

The association of ARHGAP18 with angiogenesis was first noticed in an expression profiling screen for functionally important genes during in vitro angiogenesis ${ }^{[57]}$. Later, the same group identified ARHGAP18 as an endothelial senescence-associated gene termed SENEX ${ }^{[58]}$. Relative to other RhoGAPs, ARHGAP18 expression is the highest in ECs, and its localization is predominantly cytosolic ${ }^{[59]}$. The overexpression of ARHGAP18 in EC results in an induction of premature senescence in ECs. During in vitro HUVEC tube formation, ARHGAP18 mRNA was down-regulated during the early migration phase but was later upregulated during the stabilization phase ${ }^{[58]}$.

Knockdown of ARHGAP18 promoted EC migration in a scratch wound assay. The migratory front was protrusive and irregular, with the proximal edge of the leading cell having disrupted cell junctions ${ }^{[60]}$. The increased migration was also observed in an in vitro 3D spheroid sprouting assay, with a significant increase in both sprout length and the number of sprouts. Interestingly, knockdown of ARHGAP18 in epithelial cells (MDA-MB-231 cells) resulted in delayed migration, indicating a possible cell-specific function for this protein ${ }^{[56]}$.

In vivo studies with zebrafish embryos confirmed the above in vitro findings. Knockdown of ARHGAP18 lead to enhanced angiogenic sprouting of intersegmental vessels (ISV) in zebrafish embryos. The hyper-sprouting phenotype was further characterized by increased filopodia extensions and reduced lumen diameter at least in the dorsal aorta at $24 \mathrm{hpf}$. This phenotype was vascular specific as there were no effects on lymphatic vessels ${ }^{[60]}$. Using an ex-vivo aortic ring assay, it was revealed that loss of ARHGAP18 in ARHGAP18 ${ }^{-/-}$knockout $^{-}$ mice resulted in a hyper-sprouting phenotype with a propensity to form branches instead of linear sprouts, which is reminiscent of the tip-cell phenotype ${ }^{[61]}$. Knockdown of ARHGAP18 in cultured ECs caused a higher and prolonged activation of Akt and increased mRNA expression of the tip cell marker genes such as Dll4, Flk1 and Flt4, which is consistent with additional tip cell formation ${ }^{[60]}$.

ARHGAP18 expression was localized to VE-cadherin expressing EC junctions in spheroid sprouts ${ }^{[2]}$. ARHGAP18 is dynamically regulated during angiogenesis. Upon thrombin stimulation, ARHGAP18 quickly re-localized from the cytosol to EC junctions within $2 \mathrm{~min}$ and was found at the junctional 
edges in an active junction at $10 \mathrm{~min}$. Upon achieving junctional maturity, ARHGAP18 was lost and returned to the cytosol within $60 \mathrm{~min}$. ARHGAP18 knockdown was linked to RhoC activation but not the activation of RhoA, Rac1, Cdc42 and RhoJ. Thus, ARHGAP18 seems to act as RhoCGAP and control EC junctional integrity ${ }^{[60]}$.

ARHGAP18 $/ /-$ animals developed subcutaneous B16F10 melanoma faster than wildtype mice, and the tumors were also hypervascularized, which is consistent with ARHGAP18 acting as an angiogenesis inhibitor ${ }^{[60]}$. Furthermore, ARHGAP18 is a cancer risk locus and showed loss of copy number in 30\%$56 \%$ of breast, lung and ovarian cancers ${ }^{[63-65]}$. ARHGAP18 was also down-regulated under conditions of chronic activation of rat sarcoma (RAS) and tyrosine kinase with immunoglobulinlike and EGF-like domains 1 (TIE2), often found associated with hemangiomas and venous malformations, respectively ${ }^{[66]}$. Because ARHGAP18 $1 /$ mice are phenotypically normal, targeting this protein in pathological angiogenesis could be a therapeutic possibility.

\section{Multimerin2 (MMRN2)}

Multimerin2 (MMRN2), also known as endoglyx-1, is an ECM glycoprotein that is closely associated with the cell surface. It comprises four different disulfide bonded subunits of p125, p140, p110 and p200, with an approximate molecular mass of $500 \mathrm{kDa}$. It is an EMILIN-like protein with a signal peptide, an $\mathrm{N}$-terminal EMI domain and a C-terminal C1q domain separated by a central coiled-coil rich region, and it is a member of the EDEN (EMI Domain ENdowed) protein family ${ }^{[67]}$.

MMRN2 exhibits a pan-endothelial expression in both normal and tumor vasculature, including hot spots of neovascularization in some tumors ${ }^{[68]}$. It is specifically deposited in EC in tight juxtaposition to blood vessels and is also present in the luminal side of the vessels. Nevertheless, its function in angiogenesis and EC function has remained elusive until recently.

Lorenzon et al recently discovered an anti-angiogenic role for MMRN2: it inhibits EC migration and blood vessel organization without affecting proliferation ${ }^{[69]}$. MMRN2 dosedependently impaired the formation of microvessels in a fibroblast/EC co-culture system and dramatically reduced vessel sprouting from rat aortic rings. In vivo, MMRN2 inhibits angiogenic sprouting towards a VEGF containing sponge in a CAM assay but not towards a b-FGF containing sponge ${ }^{[70]}$. Indeed, MMRN2 was found to directly bind VEGF-A with a $\mathrm{Kd}$ of $50 \mathrm{nM}$ and to interfere with VEGF/VEGFR2 signaling in ECs.

MMRN2 displaced radiolabelled VEGF bound to HUVEC cells, indicating that the protein interfered with VEGF-VEGFR binding. Consistent with the fact that MMRN2 closely associates with the EC surface, it is likely that the pericellular concentration of MMRN2 is enriched and serves as an important competitor for VEGF binding to VEGFR2, sequestering and regulating VEGF activity. Stable overexpression of MMRN2 in HT1080 human fibrosarcoma cells dramatically inhibited xenograft tumor growth in nude mice through inhibiting tumor angiogenesis ${ }^{[69]}$. Direct intratumoral injection of recom- binant MMRN2 adenovirus also led to tumor suppression and anti-angiogenic effects, although to a lesser extent ${ }^{[69]}$.

Several key features implicate MMRN2 as an attractive angiogenesis inhibitor. First, although MMRN2 exhibits panendothelial expression, it does not seem to affect normal EC growth, proliferation or apoptosis. Second, with a unique mechanism of VEGF sequestration, this ECM molecule could serve to limit local angiogenesis to either maintain a quiescent state or in pathological conditions as a feedback regulator of VEGF signaling. Indeed, most ECM members that sequester VEGF also affect EC proliferation ${ }^{[71,72]}$, but MMRN2 exhibits a unique inhibitory effect restricted to EC motility alone. Finally, the dramatic effects of MMRN2 on tumor growth and angiogenesis opens the possibility to the develop MMRN2 into a new anti-angiogenic drug for cancer therapy.

\section{Suppressor of cytokine signaling-3 (SOCS3)}

Suppressor of cytokine signaling-3 (SOCS3) belongs to the family of suppressors of cytokine signal transduction that regulate important cellular processes such as proliferation and differentiation ${ }^{[73]}$. Members of this family are transiently induced by inflammatory mediators such as lipopolysaccharide $^{[74]}$, interleukin-6 (IL-6) ${ }^{[74]}$ and tumor necrosis factor- $a$ $(\mathrm{TNF}-\mathrm{a})^{[75]}$. SOCS3 has been shown to disrupt JAK/STAT kinases and deactivates receptor tyrosine kinase signaling ${ }^{[73,76]}$.

Pathological vascular growth is often triggered by massive inflammatory and growth factor stimuli, which could be countered by endogenous angiostatic regulators. As a suppressor of inflammatory and cytokine signaling, SOCS3 is a newly identified endogenous negative regulator of angiogenesis that acts on both inflammation and growth factor-mediated vessel formation specifically in pathologic contexts ${ }^{[77]}$.

SOCS3 expression is temporally associated with pathological retinal angiogenesis. In an oxygen-induced retinopathy (OIR) model ${ }^{[7,79]}$, hypoxia-induced pathological angiogenesis peaks on postnatal day 17 (P17). This pathological angiogenesis coincided with increased TNF-a and SOCS3 expression ${ }^{[80]}$. In particular, SOCS3 expression was highly and specifically localized to pathologic retinal vessels. Given that Socs3 knockout mice are embryonic lethal ${ }^{[81]}$, a Tie2-driven EC-specific Socs3 knockout mouse (Tie2-Socs ${ }^{k o}$ ) line was generated. After being subjected to OIR, these conditional Tie2-Socs3 ${ }^{k o}$ mice exhibited increased pathological neovascularization compared to littermate controls (Socs $3^{\text {flox/flox }}$ ) at P17. Notably, Tie2-Socs $3^{k o}$ mice also exhibited normal retinal vascular development, similar rates of vascular loss during the first phase of OIR and normal vessel repair and regrowth, suggesting that SOCS3 specifically suppresses pathological angiogenesis ${ }^{[77]}$. Furthermore, when LLC (lung carcinoma) and B16F10 melanoma cells were injected into Tie2-Socs $3^{k o}$ mice, enhanced tumor growth was observed in both xenograft models with a concomitant increase in tumor vascular density ${ }^{[7]}$.

Both growth factor and inflammatory signals trigger pathological angiogenesis in OIR and cancer ${ }^{[82-85]}$. As a negative regulator of both signaling pathways, SOCS3 was shown to suppress the downstream signaling of both insulin growth 
factor-1 (IGF-1) and TNF-a. Silencing of SOCS3 expression by siRNA in ECs increased EC proliferation when stimulated with both agents. Both mTOR and STAT-3 pathways exhibited transient activation upon Socs3 silencing. This activation became sustained when ECs were pre-stimulated with TNF-a prior to IGF-1 treatment. Thus SOCS3 acted as a negative feedback regulator of growth factor signaling by modulating mTOR and STAT-3 activation ${ }^{[86]}$.

SOCS3 represents a new class of angiogenic modulators that target an integrated endothelial response rather than suppressing individual growth factors or receptors. A recent report also closely links the loss of SOCS3 to an aggressive phenotype in breast carcinoma ${ }^{[87]}$. As a novel angiogenesis inhibitor, SOCS3 has particular application potential in both proliferative retinopathy and cancer due to its specific activity toward pathological angiogenesis.

\section{Tumor protein 73-alpha (TAp73)}

TAp73 or p73-alpha is a 636-amino-acid isoform of tumor protein 73 (TP73) ${ }^{[88]}$. TP73 generates several isoforms through both alternative splicing and alternative promoter usage ${ }^{[89,90]}$. TAp73 along with the other TP73 variants are known as transactivation (TA) variants, as they all share an N-terminal transactivation domain.

The primary role of TAp73 is the transcriptional control of proapoptotic genes in the response to genotoxic stress by inhibiting p53 ${ }^{[91,92]}$. Unlike p53, a tumor suppressor gene whose mutations are widely found in human cancers, TAp73 is rarely mutated in cancer and instead is highly upregulated in several cancers ${ }^{[93,94]}$. Thus, the role of TAp73 in tumorigenesis has been elusive. On one hand, isoform specific deletion of TAp73 resulted in spontaneous and carcinogen-induced tumors, with a high incidence of lung adenocarcinomas, indicating that TAp73 is a tumor suppressor ${ }^{[95]}$. Nevertheless, the high incidence of TAp73 protein expression in cancers suggests that the protein may afford proliferative advantages to tumor cells. Indeed, a recent report supports a role for TAp73 in regulating metabolism and promoting oncogenic cell growth ${ }^{[96]}$.

TAp73 has been linked to VEGF expression with contradictory reports; however, the specific roles of TAp73 in angiogenesis are still unknown. One report attributes an inhibitory role for TAp73 in controlling VEGF expression by transcriptional repression of the VEGF promoter ${ }^{[97]}$. However, another report states that overexpression of TAp73 resulted in increased expression of VEGF at both the mRNA and protein levels ${ }^{[98]}$. A recent study by Amelio et al clarified the role of TAp73 in angiogenesis and demonstrated that TAp73 suppresses angiogenesis by promoting HIF-1a ubiquitination and degradation.

Using a two-stage chemical carcinogenesis model in mouse skin, Amelio et al showed that TAp $73^{-/-}$mice displayed accelerated initial lesion development, large tumor sizes and increased progression to squamous cell carcinoma compared to $\mathrm{TAp} 73^{+/+}$mice. Both peritumor vascularization and aortic ring angiogenesis increased in $\mathrm{TAp} 73^{-/-}$mice compared to wildtype mice ${ }^{[99]}$.
HIF-1 is a master regulator of tumor growth and angiogenesis, and its expression is under the tight control of oxygen levels within the microenvironment ${ }^{[100]}$. In the absence of $\mathrm{p} 53$, TAp73 knockdown resulted in enhanced HIF-1a expression. Nonetheless, TAp73 induced downregulation of HIF-1a in an oxygen-independent manner. TAp73 directly interacts with HIF-1a and promotes its ubiquitination and degradation, possibly functioning as a scaffold to bring HIF-1a in close proximity for subsequent ubiquitination and degradation ${ }^{[99]}$.

Accordingly, the overexpression of TAp73 led to downregulation of both VEGF-A and VEGFR2 mRNA, while stable knockdown of TAp73 in tumor cells resulted in dramatic increases in subcutaneous tumor growth and vessel density ${ }^{[99]}$. In human lung adenocarcinoma, individuals with high TAp73 expression showed significantly better prognosis, whereas HIF-1a activity and angiogenic signatures were inversely correlated with TAp73 expression ${ }^{[99]}$.

In conclusion, the tumor suppressor TAp73 has emerged as a novel inhibitor of tumor angiogenesis and plays a critical role in cancer pathogenesis. How it can be used effectively in therapeutics still requires investigation.

\section{Zinc finger protein 24 (ZNF24)}

ZNF24, also known as ZFP191 or KOX17, was identified as a member of the SCAN domain family of Krüppel-like C2H2 zinc finger transcription factors ${ }^{[101]}$. It possesses four $\mathrm{C} 2 \mathrm{H} 2$ zinc finger domains at the C-terminus that function as DNA binding domains and one scan domain in its N-terminus ${ }^{[102,103]}$. ZNF24 is ubiquitously expressed during embryonic development ${ }^{[104]}$, and ZNF24 knockout mice die prematurely at $7.5 \mathrm{~d}$ post fertilization, suggesting its key functions in normal development ${ }^{[105]}$. At the cellular level, ZNF24 is involved in the regulation of the proliferation, migration, differentiation and invasion of cells of different lineages ${ }^{[104-108]}$. In addition to regulating normal cells, ZNF24 has been shown to play perplexing roles in cancer initiation and progression.

The ZNF24 gene is located on chromosome $18 \mathrm{q} 12.1^{[109]}$ and is frequently deleted in several human cancers ${ }^{[110-113]}$. In addition, down regulation of ZNF24 mRNA expression was also observed in malignant colon and breast carcinoma ${ }^{[114,115]}$. However, ZNF24 has also been shown to promote cell proliferation of hepatocarcinoma cells ${ }^{[116]}$. ZNF24 represses VEGF transcription in MDA-MB-231 breast cancer cells in vitro and exhibits an inverse correlation with VEGF in angiogenic tumor nodules as well as malignant human colon and breast biopsies $^{[114]}$. It also represses PDGFR- $\beta$ transcription ${ }^{[117]}$, a gene known to be essential for vascular stability ${ }^{[118,119]}$.

How ZNF24 represses VEGF transcription and the in vivo consequences of this repression were recently revealed by Jia et a ${ }^{[120]}$. ZNF24 binds to an $11 \mathrm{bp}$ segment within the proximal promoter region of the VEGF gene and targets VEGF directly. This 11-bp VEGF proximal promoter region can serve as a decoy to abolish VEGF repression by ZNF24. ZNF overexpression in zebrafish resulted in decreased VEGF expression and severe vascular defects including pericardial edema, abnormal formation of caudal vascular plexus, defects in ISV formation 
and impaired circulation ${ }^{[120]}$. These defects are consistent with the VEGF knockdown phenotype.

MDA-MB-231 breast cancer cells overexpressing ZNF24 exhibited significantly reduced VEGF levels both extracellularly and intracellularly. Using an in vivo tumor cell induced dermal angiogenesis assay, MDA-MB-231 cells overexpressing ZNF24 induced significantly lower numbers of blood vessels in the injected dermal tissue compared to control cells. In addition, a high percentage of human breast cancer tissues showed significantly lower levels of ZNF24 staining, correlated with a higher VEGF level compared to adjacent normal breast tissues. These resulted suggested that ZNF24 may play a suppressive role in the initiation and/or progression of human breast cancer ${ }^{[120]}$.

Paradoxically, a recent paper from the same lab reported that ZNF24 positively regulates the angiogenic potential of human microvascular endothelial cells (HMVEC) $)^{[121]}$. They showed that knockdown of ZNF24 in HMVECs resulted in decreased cell migration, invasion, proliferation and decreased formation of vascular networks along with significantly impaired VEGFR2 signaling ${ }^{[121]}$. These results seem to suggest that ZNF24 serves as a positive stimulator of the angiogenic potential of microvascular ECs. How ZNF could exhibit divergent functions in different cell types (endothelial vs cancer cells) is very intriguing. Its role in tumor endothelium warrants further investigation.

Although ZNF24 seems to function as an inhibitor of angiogenesis in both zebrafish embryonic development and in human breast cancer by suppressing VEGF transcription $^{[120]}$, its therapeutic potential is still unclear. In addition, how ZNF24 regulates the transcription of other angiogenesisrelated genes warrant future investigation. For example, ZNF24 also represses the transcription of PDGFR- $\beta$, a gene that is important in regulating angiogenesis ${ }^{[117]}$. Elucidating the mechanisms and consequences of PDGFR- $\beta$ repression by ZNF24 would be important for fully understanding the function of this gene in angiogenesis.

\section{G-protein-coupled receptor 56 (GPR56)}

G-protein-coupled receptor (GPR56), or seven transmembrane molecule containing a long N-terminus (TM7XN1), is an atypical G-protein-coupled receptor (GPCR) that belongs to the subfamily of adhesion G-protein-coupled receptors (GPCRs). GPR56 was previously found to be anti-tumorigenic and antimetastatic in melanoma, where overexpression of GPR56 suppressed tumor growth and metastasis ${ }^{[122]}$. The expression levels of GPR56 were inversely correlated with the progression of human melanomas ${ }^{[123]}$. GPR56 was reported to exert anti-angiogenic function by inhibiting VEGF secretion/release from melanoma cells ${ }^{[123]}$. This function requires the proteolytic cleavage fragments, the extracellular $\mathrm{N}$-terminal fragment (GPRN) and the transmembrane C-terminal fragment (GPRC), to associate with each other. A 70-amino acid serine threonine proline-rich (STP) segment in the GPRN is required for this function. GPR56 inhibits VEGF secretion by inhibiting protein kinase $\mathrm{Ca}(\mathrm{PKCa})^{[123,124]}$. PKCs are proteins that regulate
VEGF release from specific granules in multiple cell types ${ }^{[125-127]}$. Hence, inhibiting PKCa prevents VEGF release from melanoma cells and inhibits angiogenesis.

GPR56 is the first adhesion GPCR attributed with anti-angiogenic function. Moreover, its anti-angiogenic mechanism of preventing VEGF release at the source is unique. Thus, GPR56 complements the current anti-angiogenic drugs and raises the efficacy of these drugs, which do not inhibit the production of VEGF. GPR56 can also be used as a prognostic marker as GPR56 down-regulation is correlated with melanoma progression.

\section{JWA}

JWA is also known as Prenylated Rab acceptor 1 domain family member 3 (PRAF3) and ADP-ribosylation factor-like 6 interacting protein 5 (ARL6IP5) ${ }^{[128]}$. It is part of the prenylated rab acceptor 1 domain family (PRAF), whose members are involved in intracellular protein transport. JWA functions as a microtubule-binding protein and is involved in the mitogen activated protein kinase (MAPK) signaling pathway, regulating cancer cell migration ${ }^{[129]}$. Tumor suppressor functions such as inducing apoptosis ${ }^{[129]}$, inhibiting metastasis in melanoma ${ }^{[130]}$, osteosarcoma, breast and cervical cancers have also been reported ${ }^{[128]}$. Recently, JWA was found to function as a tumor angiogenesis inhibitor in melanoma and gastric cancer $^{[131,132]}$. Overexpression of JWA in melanoma and gastric cancer cell lines inhibited angiogenesis in vitro and in vivo.

Different anti-angiogenic mechanisms for JWA exist in melanoma and gastric cancer. In melanoma, JWA suppresses angiogenesis by down-regulating integrin-linked kinase (ILK) expression through integrin $\operatorname{av} \beta 3$ and transcription factor $\mathrm{Sp} 1^{[130]}$. ILK signaling activates NF-kB/IL-6/STAT3/VEGF angiogenic signaling pathways. JWA overexpression significantly inhibited IL6 and VEGF expression, but this inhibition is lost when ILK is also overexpressed. By suppressing ILK expression, JWA inhibits melanoma angiogenesis. Regarding gastric cancer, JWA down-regulates the expression of MMP2, a pro-angiogenic molecule. Down-regulation of MMP-2 expression is also through inhibiting transcription factor Sp1 via an ubiquitin-proteasome dependent mechanism ${ }^{[132]}$.

To the best of our knowledge, JWA is the first microtubulebinding protein that has been shown to have anti-angiogenic function. JWA thus has the potential to be developed into an attractive therapeutic drug for cancer and other angiogenesisrelated illnesses. JWA expression correlates with melanoma survival. Patients with melanoma expressing high levels of JWA and low levels of ILK had significantly increased 5-year survival rates ${ }^{[133]}$. Similarly for gastric cancer, patients with high JWA and low MMP2 had better survival rates ${ }^{[132]}$. Hence, JWA can be both a prognostic marker and a potential therapeutic for melanoma and gastric cancer.

\section{Conclusion}

Angiogenesis inhibitors play important roles in regulating both physiology and pathology. Endogenous protein inhibitors have the advantage of low toxicity, high tolerance, low 


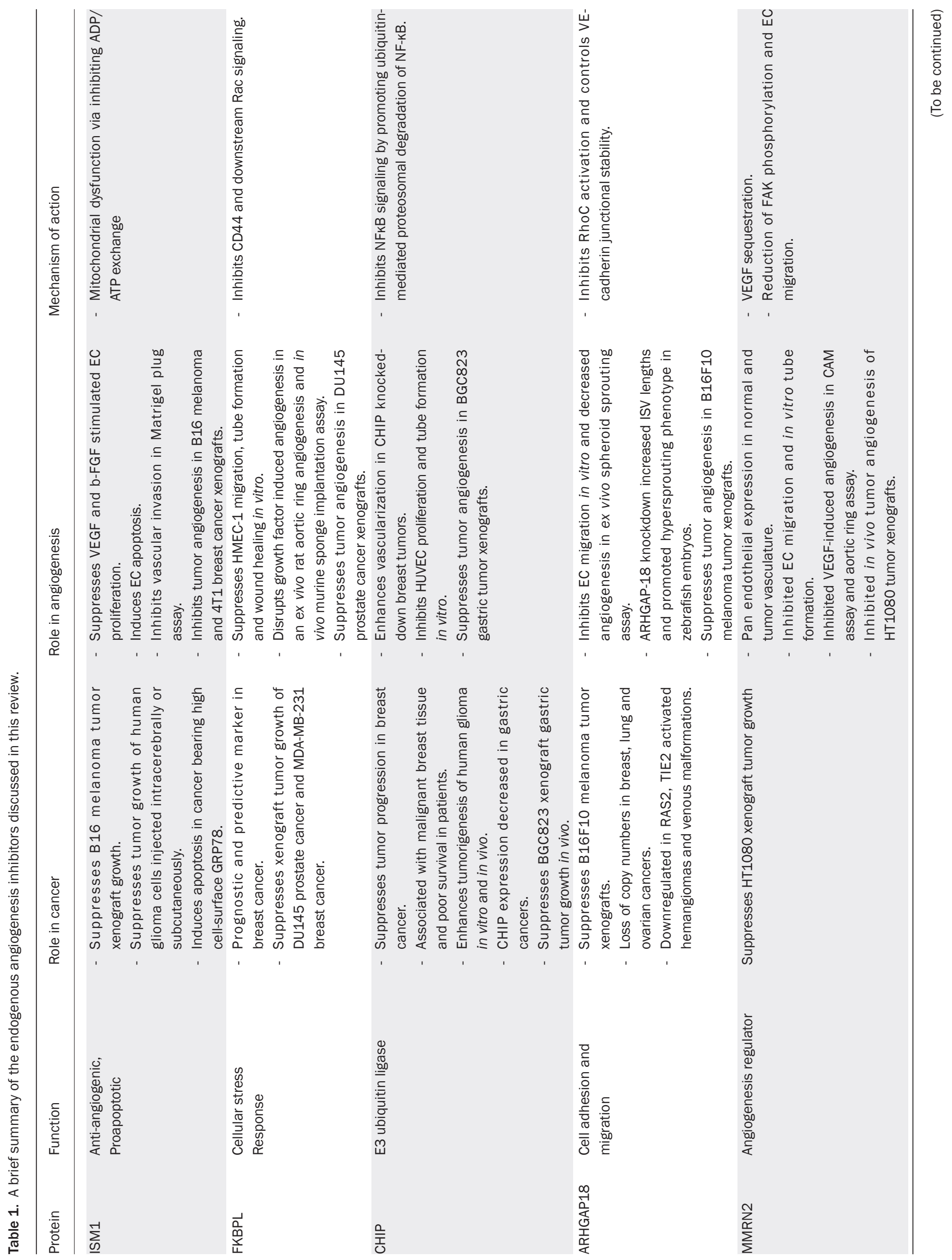




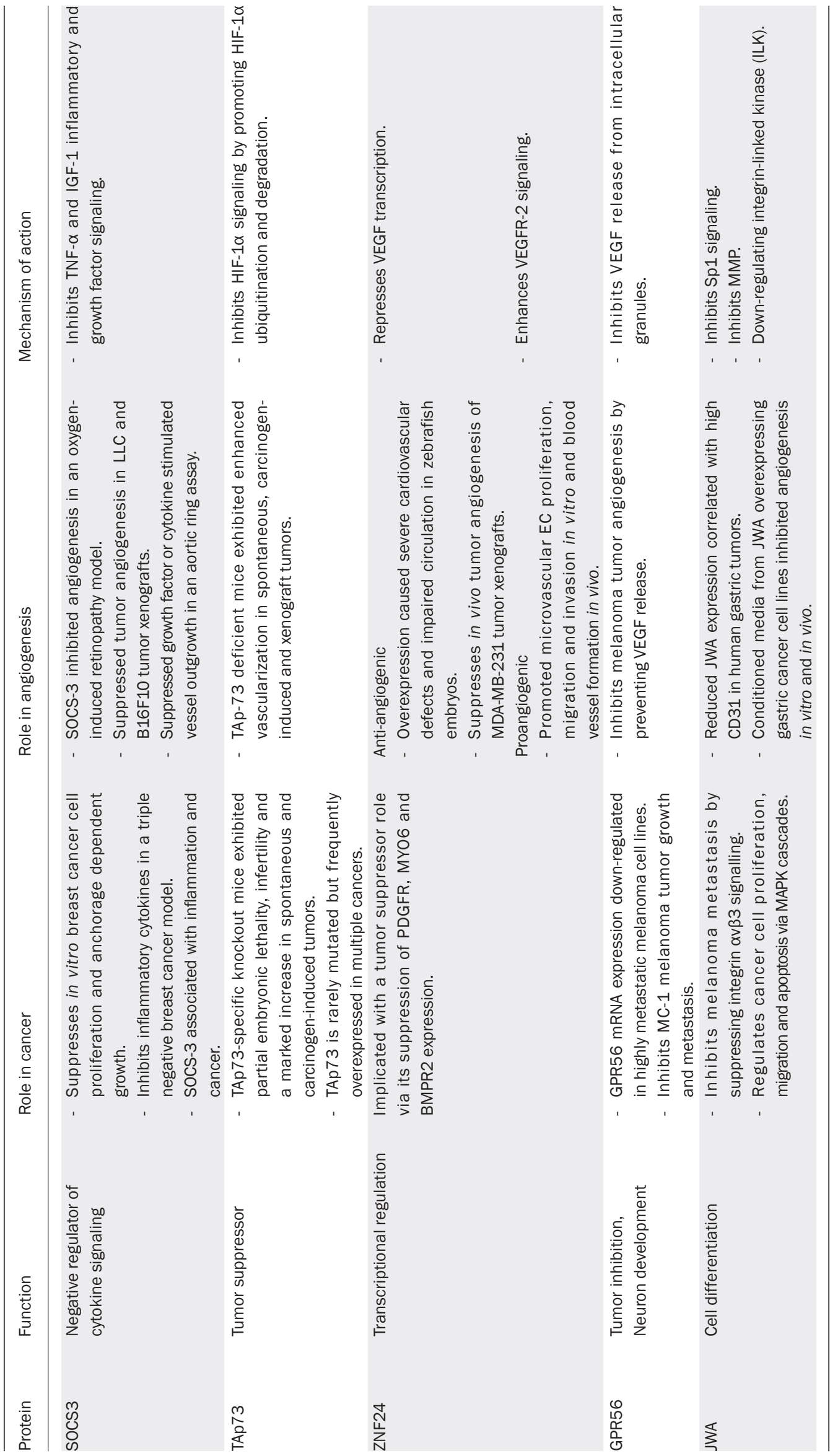


risk of drug resistance and a higher chance of specifically blocking pathological neovascularization, without affecting the normal vasculature ${ }^{[134,135]}$.

Over the years, many endogenous angiogenesis inhibitors have been discovered, and some of them have reached clinical trial stages or are already in the market; these include endostatin (Endostar) and angiostatin ${ }^{[136-139]}$. Other inhibitors have served as parent molecules from which derivative analogues have been developed and reached clinical trial stage, such as thrombospondin- 1 and its analogue ABT-510 $0^{[140]}$. Nevertheless, to date, clinical efficacy in humans is still questionable. Only endostar, a modified recombinant endostatin, has been approved as an anticancer drug in China. In addition, the anti-angiogenic drugs currently in clinical use are predominantly based on inhibiting VEGF signaling pathways. Lack of long-term therapeutic efficacy and the development of drug resistance are prevalent with the current drugs. This under- scores the importance of discovering novel angiogenesis inhibitors to not only fully understand the biology of angiogenesis regulation but also identify unique mechanisms of action and additional cellular targets to design more effective drugs.

In this review, we selectively presented ten novel endogenous angiogenesis inhibitors discovered in the past five years. All of these inhibitors have demonstrated inhibitory roles in pathological angiogenesis such as in cancer, retinopathy or fracture healing (summarized in Table 1) but do not affect normal physiological angiogenesis. These proteins have various subcellular localizations including secreted/extracellular (isthmin, FKBPL and multimerin-2), transmembrane (GPR56), cytoplasmic (CHIP, ARHGAP18, SOCS-3, TAp73 and JWA) and nuclear (ZNF24). Each of the proteins has distinct and diverse mechanisms of action (summarized in Figures 1 and 2) including the prevention of VEGF release, VEGF sequestration, promoting proteosomal degradation of angiogenesis

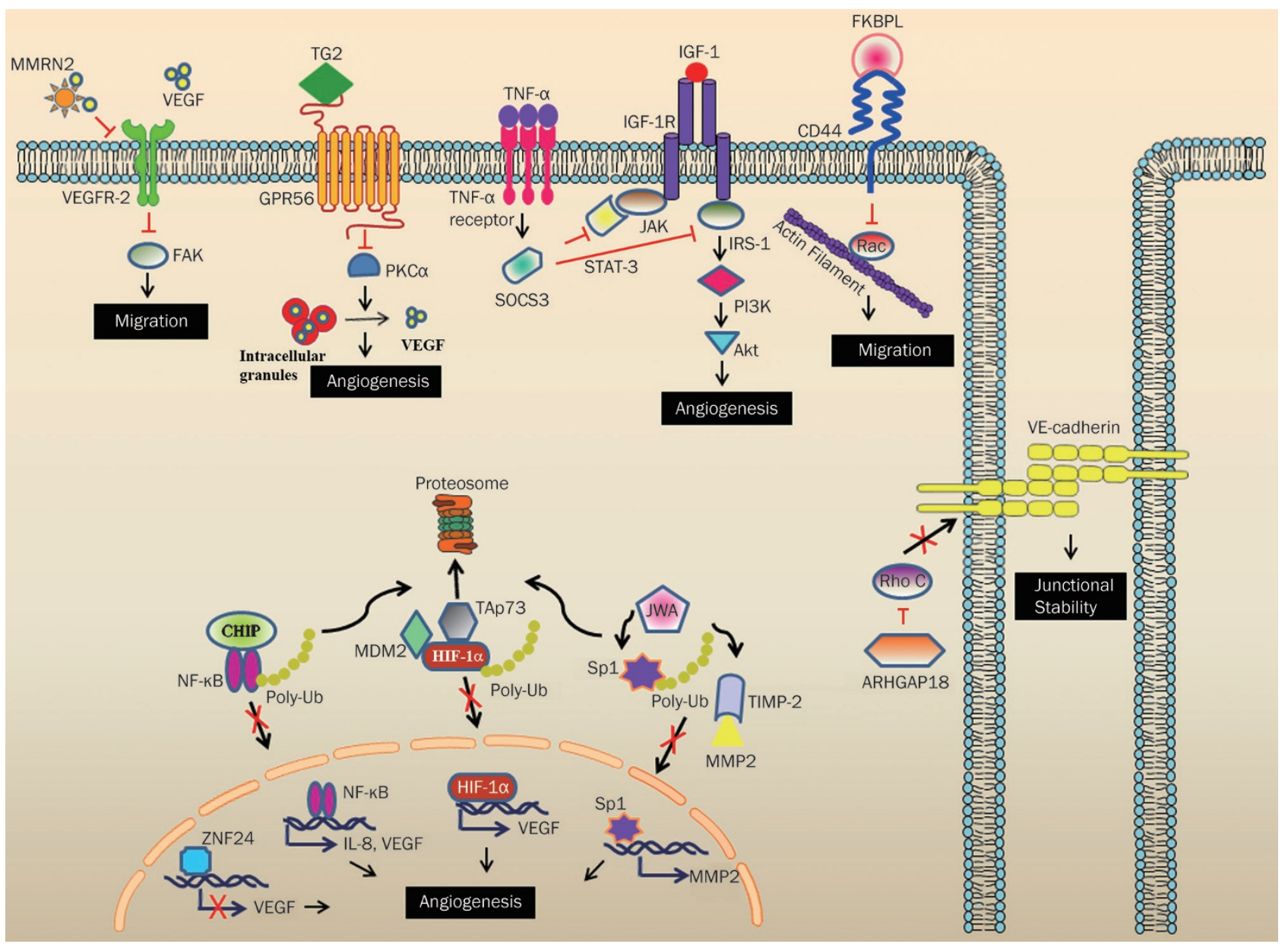

Figure 2. Mechanism of action of endogenous angiogenesis inhibitors. Angiogenesis inhibitors affect the fundamental processes leading to angiogenesis such as proliferation, survival, adhesion, migration and junctional stability. The secreted angiogenesis inhibitors such as MMRN2 and FKBPL act on specific cell surface receptors modulating their pro-angiogenic function. In the case of membrane proteins such as GPR56, binding to its specific ligand results in the activation of a signaling cascade leading to angiogenic inhibition. The cytoplasmic angiogenesis inhibitors such as CHIP, TAp73 and JWA function via a common mechanism: by promoting proteosomal degradation of their cellular targets, thereby preventing their nuclear translocation and subsequent action. ARHGAP18 achieves angiogenic inhibition via influencing EC junctional stability. Finally, ZNF24 acts via transcriptional repression of the angiogenic stimulator VEGF. 
stimulators, or interfering with multiple angiogenic stimulator signaling pathways. Thus, these proteins have great potential to function as anti-angiogenic drugs. Further studies on these proteins will expand our understanding of their biology and help to design efficacious drugs for angiogenesis-related diseases. In addition, molecules such as CHIP, TAp73, GPR56 and JWA have been shown to have an inverse correlation with several types of human cancers and could potentially also serve as prognostic markers.

\section{References}

1 Folkman J. Angiogenesis in cancer, vascular, rheumatoid and other disease. Nat Med 1995; 1: 27-31.

2 Carmeliet P, Jain RK. Angiogenesis in cancer and other diseases. Nature 2000; 407: 249-57.

3 Hanahan D, Folkman J. Patterns and emerging mechanisms of the angiogenic switch during tumorigenesis. Cell 1996; 86: 353-64.

4 Hanahan D, Weinberg RA. Hallmarks of cancer: the next generation. Cell 2011; 144: 646-74.

5 Hanahan D, Weinberg RA. The hallmarks of cancer. Cell 2000; 100: 57-70.

6 Lawler J. Thrombospondin-1 as an endogenous inhibitor of angiogenesis and tumor growth. J Cell Mol Med 2002; 6: 1-12.

7 Streit M, Riccardi L, Velasco P, Brown LF, Hawighorst T, Bornstein P, et al. Thrombospondin-2: A potent endogenous inhibitor of tumor growth and angiogenesis. Proc Natl Acad Sci U S A 1999; 96: 14888-93.

8 Watanabe K, Hasegawa Y, Yamashita H, Shimizu K, Ding YY, Abe $\mathrm{M}$, et al. Vasohibin as an endothelium-derived negative feedback regulator of angiogenesis. J Clin Invest 2004; 114: 898-907.

9 Hiraki $\mathrm{Y}$, Inoue H, Iyama K, Kamizono A, Ochiai M, Shukunami C, et al. Identification of chondromodulin I as a novel endothelial cell growth inhibitor - Purification and its localization in the avascular zone of epiphysical cartilage. J Biol Chem 1997; 272: 32419-26.

10 Dawson DW, Volpert OV, Gillis P, Crawford SE, Xu H, Benedict W, et al. Pigment epithelium-derived factor: a potent inhibitor of angiogenesis. Science 1999; 285: 245-8.

11 Bikfalvi A, Gimenez-Gallego G. The control of angiogenesis and tumor invasion by platelet factor-4 and platelet factor-4-derived molecules. Semin Thromb Hemost 2004; 30: 137-44.

12 OReilly MS, Boehm T, Shing Y, Fukai N, Vasios G, Lane WS, et al. Endostatin: An endogenous inhibitor of angiogenesis and tumor growth. Cell 1997; 88: 277-85.

13 Oreilly MS, Holmgren L, Shing Y, Chen C, Rosenthal RA, Moses M, et al. Angiostatin - a novel angiogenesis inhibitor that mediates the suppression of metastases by a Lewis lung-carcinoma. Cell 1994; 79: 315-28.

14 Maeshima Y, Colorado PC, Torre A, Holthaus KA, Grunkemeyer JA, Ericksen MB, et al. Distinct antitumor properties of a type IV collagen domain derived from basement membrane. J Biol Chem 2000; 275 : 21340-8.

15 Saran Kumar NR, Shruthi Venugopal, Ruowen Ge. Endogenous Angiogenesis Inhibitors: Is The List Ever Ending? In: Berhardt LV editors. Advances in Medicine and Biology ed: Nova Science Publishers 2012: 1-48.

16 Pera EM, Kim JI, Martinez SL, Brechner M, Li SY, Wessely O, et al. Isthmin is a novel secreted protein expressed as part of the Fgf-8 synexpression group in the Xenopus midbrain-hindbrain organizer. Mech Develop 2002; 116: 169-72.

17 Xiang W, Ke ZY, Zhang Y, Cheng GHY, Irwan ID, Sulochana KN, et al. Isthmin is a novel secreted angiogenesis inhibitor that inhibits tumour growth in mice. J Cell Mol Med 2011; 15: 359-74.

18 Chen M, Zhang Y, Yu VC, Chong YS, Yoshioka T, Ge R. Isthmin targets cell-surface GRP78 and triggers apoptosis via induction of mitochondrial dysfunction. Cell Death Differ 2014; 21: 797-810.

19 Zhang Y, Chen M, Venugopal S, Zhou Y, Xiang W, Li YH, et al. Isthmin exerts pro-survival and death-promoting effect on endothelial cells through alphavbeta5 integrin depending on its physical state. Cell Death Dis 2011; 2: e153.

20 Ni M, Zhang Y, Lee AS. Beyond the endoplasmic reticulum: atypical GRP78 in cell viability, signalling and therapeutic targeting. Biochem J 2011: 434: 181-8.

21 Klingenberg M. The ADP and ATP transport in mitochondria and its carrier. Biochim Biophys Acta 2008; 1778: 1978-2021.

22 Lee AS. GRP78 induction in cancer: Therapeutic and prognostic implications. Cancer Res 2007; 67: 3496-9.

23 Schwarze S, Rangnekar VM. Targeting plasma membrane GRP78 for cancer growth inhibition. Cancer Biol Ther 2010; 9: 153-5.

24 Sato M, Yao VJ, Arap W, Pasqualini R. GRP78 signaling hub a receptor for targeted tumor therapy. Adv Genet 2010; 69: 97-114.

25 Yuan BQ, Xian RH, Ma JF, Chen YJ, Lin CG, Song YM. Isthmin inhibits glioma growth through antiangiogenesis in vivo. J Neuro Oncol 2012; 109: 245-52.

26 Robson T, Joiner MC, Wilson GD, McCullough W, Price ME, Logan I, et al. A novel human stress response-related gene with a potential role in induced radioresistance. Radiat Res 1999; 152: 451-61.

27 Robson T, Price ME, Moore ML, Joiner MC, McKelvey-Martin VJ, McKeown SR, et al. Increased repair and cell survival in cells treated with DIR1 antisense oligonucleotides: implications for induced radioresistance. Int J Radiat Biol 2000; 76: 617-23.

28 Kay JE. Structure-function relationships in the FK506-binding protein (FKBP) family of peptidylprolyl cis-trans isomerases. Biochem J 1996; 314: 361-85.

29 McKeen HD, McAlpine K, Valentine A, Quinn DJ, McClelland K, Byrne C, et al. A novel FK506-like binding protein interacts with the glucocorticoid receptor and regulates steroid receptor signaling. Endocrinology 2008; 149: 5724-34.

30 Sunnotel O, Hiripi L, Lagan K, McDaid JR, De Leon JM, Miyagawa Y, et al. Alterations in the steroid hormone receptor co-chaperone FKBPL are associated with male infertility: a case-control study. Reprod Biol Endocrinol 2010; 8: 22.

31 Mckeen HD, Byrne C, Jithesh PV, Donley C, Valentine A, Yakkundi A, et al. FKBPL regulates estrogen receptor signaling and determines response to endocrine therapy. Cancer Res 2010; 70: 1090-100.

32 Pfosser A, Thalgott M, Buttner K, Brouet A, Feron O, Boekstegers $\mathrm{P}$, et al. Liposomal Hsp90 cDNA induces neovascularization via nitric oxide in chronic ischemia. Cardiovasc Res 2005; 65: 728-36.

33 Kaur G, Belotti D, Burger AM, Fisher-Nielson K, Borsotti P, Riccardi E, et al. Antiangiogenic properties of 17-(dimethylaminoethylamino)-17demethoxygeldanamycin: an orally bioavailable heat shock protein 90 modulator. Clin Cancer Res 2004; 10: 4813-21.

34 Valentine A, O'Rourke M, Yakkundi A, Worthington J, Hookham M, Bicknell R, et al. FKBPL and peptide derivatives: novel biological agents that inhibit angiogenesis by a CD44-dependent mechanism. Clin Cancer Res 2011; 17: 1044-56.

35 Cao G, Savani RC, Fehrenbach M, Lyons C, Zhang L, Coukos G, et al. Involvement of endothelial CD44 during in vivo angiogenesis. Am J Pathol 2006; 169: 325-36.

36 Bourguignon LYW. Hyaluronan-mediated CD44 activation of RhoGTPase signaling and cytoskeleton function promotes tumor progression. Semin Cancer Biol 2008; 18: 251-9. 
37 Crabb SJ, Patsios D, Sauerbrei E, Ellis PM, Arnold A, Goss G, et al. Tumor cavitation: impact on objective response evaluation in trials of angiogenesis inhibitors in non-small-cell lung cancer. J Clin Oncol 2009; 27: 404-10.

38 Verheul HM, Pinedo HM. Possible molecular mechanisms involved in the toxicity of angiogenesis inhibition. Nat Rev Cancer 2007; 7: 475-85.

39 Esser C, Alberti S, Hohfeld J. Cooperation of molecular chaperones with the ubiquitin/proteasome system. Biochim Biophys Acta 2004; 1695: 171-88.

40 Connell P, Ballinger CA, Jiang J, Wu Y, Thompson L, Hohfeld J, et al. The co-chaperone $\mathrm{CHIP}$ regulates protein triage decisions mediated by heat-shock proteins. Nat Cell Biol 2001; 3: 93-6.

41 Muller P, Hrstka R, Coomber D, Lane DP, Vojtesek B. Chaperonedependent stabilization and degradation of p53 mutants. Oncogene 2008; 27: 3371-83.

42 Fan MY, Park A, Nephew KP. CHIP (carboxyl terminus of Hsc70interacting protein) promotes basal and geldanamycin-induced degradation of estrogen receptor-alpha. Mol Endocrinol 2005; 19 : 2901-14.

43 Xu WP, Marcu M, Yuan XT, Mimnaugh E, Patterson C, Neckers L. Chaperone-dependent E3 ubiquitin ligase CHIP mediates a degradative pathway for c-ErbB2 Neu. Proc Natl Acad Sci U S A 2002; 99: 12847-52.

44 Kamynina E, Kauppinen K, Duan FP, Muakkassa N, Manor D. Regulation of proto-oncogenic $\mathrm{Dbl}$ by chaperone-controlled, ubiquitinmediated degradation. Mol Cell Biol 2007; 27: 1809-22.

45 Xin H, Xu XL, Li LY, Ning HX, Rong Y, Shang Y, et al. CHIP controls the sensitivity of transforming growth factor-beta signaling by modulating the basal level of Smad3 through ubiquitin-mediated degradation. J Biol Chem 2005; 280: 20842-50.

46 Bento CF, Fernandes R, Ramalho J, Marques C, Shang F, Taylor A, et al. The chaperone-dependent ubiquitin ligase CHIP targets HIF1alpha for degradation in the presence of methylglyoxal. PLoS One 2010; 5: e15062.

47 Shang Y, Zhao X, Xu X, Xin H, Li X, Zhai Y, et al. CHIP functions an E3 ubiquitin ligase of Runx1. Biochem Biophys Res Commun 2009; 386: 242-6.

48 Jang KW, Lee JE, Kim SY, Kang MW, Na MH, Lee CS, et al. The C-terminus of Hsp70-interacting protein promotes Met receptor degradation. J Thorac Oncol 2011; 6 : 679-87.

49 Kajiro M, Hirota R, Nakajima Y, Kawanowa K, So-Ma K, Ito I, et al. The ubiquitin ligase CHIP acts as an upstream regulator of oncogenic pathways. Nat Cell Biol 2009; 11: 312-9.

50 Xu T, Zhou Q, Zhou J, Huang Y, Yan Y, Li W, et al. Carboxyl terminus of Hsp70-interacting protein (CHIP) contributes to human glioma oncogenesis. Cancer Sci 2011; 102: 959-66.

51 Plate KH, Scholz A, Dumont DJ. Tumor angiogenesis and antiangiogenic therapy in malignant gliomas revisited. Acta Neuropathol 2012; 124: 763-75.

52 Wang SY, Wu XM, Zhang JB, Chen YS, Xu J, Xia XW, et al. CHIP functions as a novel suppressor of tumour angiogenesis with prognostic significance in human gastric cancer. Gut 2013; 62: 496-508.

53 Nurnberg W, Tobias D, Otto F, Henz BM, Schadendorf D. Expression of interleukin-8 detected by in situ hybridization correlates with worse prognosis in primary cutaneous melanoma. J Pathol 1999; 189: 546-51.

54 Sparmann A, Bar-Sagi D. Ras-induced interleukin-8 expression plays a critical role in tumor growth and angiogenesis. Cancer Cell 2004; 6: 447-58.
55 Li X, Liu Q, Liu S, Zhang J, Zhang Y. New member of the guanosine triphosphatase activating protein family in the human epididymis. Acta Biochim Biophys Sin 2008; 40: 855-63.

56 Maeda M, Hasegawa H, Hyodo T, Ito S, Asano E, Yuang H, et al. ARHGAP18, a GTPase-activating protein for RhoA, controls cell shape, spreading, and motility. Mol Biol Cell 2011; 22: 3840-52.

57 Hahn CN, Su ZJ, Drogemuller CJ, Tsykin A, Waterman SR, Brautigan $\mathrm{PJ}$, et al. Expression profiling reveals functionally important genes and coordinately regulated signaling pathway genes during in vitro angiogenesis. Physiol Genomics 2005; 22: 57-69.

58 Coleman PR, Hahn CN, Grimshaw M, Lu Y, Li X, Brautigan PJ, et al. Stress-induced premature senescence mediated by a novel gene, SENEX, results in an anti-inflammatory phenotype in endothelial cells. Blood 2010; 116: 4016-24.

59 van Buul JD, Geerts D, Huveneers S. Rho GAPs and GEFs: controling switches in endothelial cell adhesion. Cell Adh Migr 2014; 8: 10824.

60 Chang GH, Lay AJ, Ting KK, Zhao Y, Coleman PR, Powter EE, et al. ARHGAP18: an endogenous inhibitor of angiogenesis, limiting tip formation and stabilizing junctions. Small GTPases 2014; 5: 1-15.

61 Blanco R, Gerhardt H. VEGF and Notch in tip and stalk cell selection. Cold Spring Harb Perspect Med 2013; 3: a006569.

62 Rabiet MJ, Plantier JL, Rival Y, Genoux Y, Lampugnani MG, Dejana E. Thrombin-induced increase in endothelial permeability is associated with changes in cell-to-cell junction organization. Arterioscler Thromb Vasc Biol 1996; 16: 488-96.

63 Hu X, Stern HM, Ge L, O'Brien C, Haydu L, Honchell CD, et al. Genetic alterations and oncogenic pathways associated with breast cancer subtypes. Mol Cancer Res 2009; 7: 511-22.

64 Stefansson OA, Jonasson JG, Olafsdottir K, Bjarnason H, Th Johannsson O, Bodvarsdottir SK, et al. Genomic and phenotypic analysis of BRCA2 mutated breast cancers reveals co-occurring changes linked to progression. Breast Cancer Res 2011; 13: R95.

65 Forbes SA, Bindal N, Bamford S, Cole C, Kok CY, Beare D, et al. COSMIC: mining complete cancer genomes in the Catalogue of Somatic Mutations in Cancer. Nucleic Acids Res 2011; 39: D94550.

66 Uebelhoer M, Natynki M, Kangas J, Mendola A, Nguyen HL, Soblet J, et al. Venous malformation-causative TIE2 mutations mediate an AKT-dependent decrease in PDGFB. Hum Mol Genet 2013; 22 : 3438-48.

67 Paulsson M, Heinegård D. Radioimmunoassay of the 148-kilodalton cartilage protein. Distribution of the protein among bovine tissues. Biochem J 1982; 207: 207-13.

68 Christian S, Ahorn H, Novatchkova M, Garin-Chesa P, Park JE, Weber G, et al. Molecular cloning and characterization of EndoGlyx-1, an EMILIN-like multisubunit glycoprotein of vascular endothelium. J Biol Chem 2001; 276: 48588-95.

69 Sanz-Moncasi MP, Garin-Chesa P, Stockert E, Jaffe EA, Old L, Rettig WJ. Identification of a high molecular weight endothelial cell surface glycoprotein, endoGlyx-1, in normal and tumor blood vessels. Lab Invest 1994; 71: 366-73.

70 Lorenzon E, Colladel R, Andreuzzi E, Marastoni S, Todaro F, Schiappacassi M, et al. MULTIMERIN2 impairs tumor angiogenesis and growth by interfering with VEGF-A/VEGFR2 pathway. Oncogene 2012; 31: 3136-47.

71 Ribatti D, Nico B, Vacca A, Presta M. The gelatin spongechorioallantoic membrane assay. Nat Protoc 2006; 1: 85-91.

72 Kupprion C, Motamed K, Sage EH. SPARC (BM-40, osteonectin) inhibits the mitogenic effect of vascular endothelial growth factor on microvascular endothelial cells. J Biol Chem 1998; 273: 29635-40. 
73 Sahni A, Francis CW. Vascular endothelial growth factor binds to fibrinogen and fibrin and stimulates endothelial cell proliferation. Blood 2000; 96: 3772-8.

74 Starr R, Willson TA, Viney EM, Murray $\amalg$, Rayner JR, Jenkins BJ, et al. A family of cytokine-inducible inhibitors of signalling. Nature 1997; 387: 917-21.

75 Lebel E, Vallieres L, Rivest S. Selective involvement of interleukin-6 in the transcriptional activation of the suppressor of cytokine signaling-3 in the brain during systemic immune challenges. Endocrinology 2000; 141: 3749-63.

76 Jiang Y, Zhang Q, Soderland C, Steinle JJ. TNFalpha and SOCS3 regulate IRS-1 to increase retinal endothelial cell apoptosis. Cell Signal 2012; 24: 1086-92.

77 Dey BR, Furlanetto RW, Nissley P. Suppressor of cytokine signaling (SOCS)-3 protein interacts with the insulin-like growth factor-I receptor. Biochem Biophys Res Commun 2000; 278: 38-43.

78 Stahl A, Joyal JS, Chen J, Sapieha P, Juan AM, Hatton CJ, et al. SOCS3 is an endogenous inhibitor of pathologic angiogenesis. Blood 2012; 120: 2925-9.

79 Smith LE, Wesolowski E, McLellan A, Kostyk SK, D'Amato R, Sullivan R, et al. Oxygen-induced retinopathy in the mouse. Invest Ophthalmol Vis Sci 1994; 35: 101-11.

80 Stahl A, Connor KM, Sapieha P, Chen J, Dennison RJ, Krah NM, et al. The mouse retina as an angiogenesis model. Invest Ophthalmol Vis Sci 2010; 51: 2813-26.

81 Sapieha P, Stahl A, Chen J, Seaward MR, Willett KL, Krah NM, et al. 5-Lipoxygenase metabolite 4-HDHA is a mediator of the antiangiogenic effect of omega-3 polyunsaturated fatty acids. Sci TransI Med 2011; 3:69ra12.

82 Roberts AW, Robb L, Rakar S, Hartley L, Cluse L, Nicola NA, et al. Placental defects and embryonic lethality in mice lacking suppressor of cytokine signaling 3. Proc Natl Acad Sci U S A 2001; 98: 9324-9.

83 Lofqvist C, Willett KL, Aspegren O, Smith AC, Aderman CM, Connor $\mathrm{KM}$, et al. Quantification and localization of the IGF/insulin system expression in retinal blood vessels and neurons during oxygeninduced retinopathy in mice. Invest Ophthalmol Vis Sci 2009; 50: 1831-7.

84 Shaw LC, Pan H, Afzal A, Calzi SL, Spoerri PE, Sullivan SM, et al. Proliferating endothelial cell-specific expression of IGF-I receptor ribozyme inhibits retinal neovascularization. Gene Ther 2006; 13: 752-60.

85 Sasi SP, Yan X, Enderling H, Park D, Gilbert HY, Curry C, et al. Breaking the 'harmony' of TNF-alpha signaling for cancer treatment. Oncogene 2012; 31: 4117-27.

86 Kociok N, Radetzky S, Krohne TU, Gavranic C, Joussen AM. Pathological but not physiological retinal neovascularization is altered in TNF-Rp55-receptor-deficient mice. Invest Ophthalmol Vis Sci 2006; 47: 5057-65.

87 Stahl A, Joyal JS, Chen J, Sapieha P, Juan AM, Hatton CJ, et al. SOCS3 is an endogenous inhibitor of pathologic angiogenesis. Blood 2012; 120: 2925-9.

88 Ying MZ, Li DW, Yang LJ, Wang M, Wang N, Chen Y, et al. Loss of SOCS3 expression is associated with an increased risk of recurrent disease in breast carcinoma. J Cancer Res Clin 2010; 136: 161726.

89 Kaghad M, Bonnet H, Yang A, Creancier L, Biscan JC, Valent A, et al. Monoallelically expressed gene related to p53 at 1p36, a region frequently deleted in neuroblastoma and other human cancers. Cell 1997; 90: 809-19.

90 De Laurenzi V, Costanzo A, Barcaroli D, Terrinoni A, Falco M, Annicchiarico-Petruzzelli $\mathrm{M}$, et al. Two new p73 splice variants, gamma and delta, with different transcriptional activity. J Exp Med 1998; 188: 1763-8.

91 Nozell S, Wu Y, McNaughton K, Liu G, Willis A, Paik JC, et al. Characterization of p73 functional domains necessary for transactivation and growth suppression. Oncogene 2003; 22 : 4333-47.

92 Wang JL, Liu X, Hande MP, Wong AC, Jin YJ, Yin YX. TAp73 is a downstream target of $p 53$ in controlling the cellular defense against stress. J Biol Chem 2007; 282: 29152-62.

93 Chen DS, Ming LH, Zou FD, Peng Y, Van Houten B, Yu J, et al. TAp73 promotes cell survival upon genotoxic stress by inhibiting p53 activity. Oncotarget 2014; 5: 8107-22.

94 Muller PA, Vousden KH. p53 mutations in cancer. Nat Cell Biol 2013; 15: 2-8.

95 Benard J, Douc-Rasy S, Ahomadegbe JC. TP53 family members and human cancers. Hum Mutat 2003; 21: 182-91.

96 Tomasini R, Tsuchihara K, Wilhelm M, Fujitani M, Rufini A, Cheung $\mathrm{CC}$, et al. TAp73 knockout shows genomic instability with infertility and tumor suppressor functions. Gene Dev 2008; 22: 2677-91.

97 Du W, Jiang P, Mancuso A, Stonestrom A, Brewer MD, Minn AJ, et al. TAp73 enhances the pentose phosphate pathway and supports cell proliferation. Nat Cell Biol 2013; 15: 991-1000.

98 Salimath B, Marme D, Finkenzeller G. Expression of the vascular endothelial growth factor gene is inhibited by p73. Oncogene 2000; 19: 3470-6.

99 Vikhanskaya F, Bani MR, Borsotti P, Ghilardi C, Ceruti R, Ghisleni $G$, et al. p73 Overexpression increases VEGF and reduces thrombospondin-1 production: implications for tumor angiogenesis. Oncogene 2001; 20: 7293-300.

100 Amelio I, Inoue S, Markert EK, Levine AJ, Knight RA, Mak TW, et al. TAp73 opposes tumor angiogenesis by promoting hypoxia-inducible factor 1 alpha degradation. Proc Natl Acad Sci U S A 2015; 112: 226-31.

101 Lu X, Kang Y. Hypoxia and hypoxia-inducible factors: master regulators of metastasis. Clin Cancer Res 2010; 16: 5928-35.

102 Han ZG, Zhang QH, Ye M, Kan LX, Gu BW, He KL, et al. Molecular cloning of six novel Kruppel-like zinc finger genes from hematopoietic cells and identification of a novel transregulatory domain KRNB. J Biol Chem 1999; 274: 35741-8.

103 Wang HY, Sun RL, Liu GX, Yao MH, Fei J, Shen HB. Characterization of the target DNA sequence for the DNA-binding domain of zinc finger protein 191. Acta Biochim Biophys Sin 2008; 40: 704-10.

104 Edelstein LC, Collins T. The SCAN domain family of zinc finger transcription factors. Gene 2005; 359: 1-17.

105 Khalfallah O, Faucon-Biguet N, Nardelli J, Meloni R, Mallet J. Expression of the transcription factor Zfp191 during embryonic development in the mouse. Gene Expr Patterns 2008; 8: 148-54.

106 Li JZ, Chen X, Yang H, Wang SL, Guo BY, Yu L, et al. The zinc finger transcription factor 191 is required for early embryonic development and cell proliferation. Exp Cell Res 2006; 312: 3990-8.

107 Howng SYB, Avila RL, Emery B, Traka M, Lin WS, Watkins T, et al. ZFP191 is required by oligodendrocytes for CNS myelination. Gene Dev 2010; 24: 301-11.

108 Lv L, Zhang J, Wang P, Meng Q, Liang W, Zhang L. Zinc finger protein 191 deficiency attenuates vascular smooth muscle cell proliferation, migration, and intimal hyperplasia after endovascular arterial injury. J Vasc Surg 2014; 59: 500-9.

109 Rousseau-Merck MF, Huebner K, Berger R, Thiesen HJ. Chromosomal localization of two human zinc finger protein genes, ZNF24 (KOX17) and ZNF29 (KOX26), to 18q12 and 17p13-p12, respectively. Genomics 1991; 9: 154-61. 
110 Kern SE, Fearon ER, Tersmette KW, Enterline JP, Leppert M, Nakamura $Y$, et al. Clinical and pathological associations with allelic loss in colorectal carcinoma. JAMA 1989; 261: 3099-103.

111 Vogelstein B, Fearon ER, Hamilton SR, Kern SE, Preisinger AC, Leppert M, et al. Genetic alterations during colorectal-tumor development. N Engl J Med 1988; 319: 525-32.

112 Papadimitrakopoulou VA, Oh Y, El-Naggar A, Izzo J, Clayman G, Mao L. Presence of multiple incontiguous deleted regions at the long arm of chromosome 18 in head and neck cancer. Clin Cancer Res 1998; 4: 539-44.

113 Richard F, Pacyna-Gengelbach M, Schluns K, Fleige B, Winzer KJ, Szymas J, et al. Patterns of chromosomal imbalances in invasive breast cancer. Int J Cancer 2000; 89: 305-10.

114 Harper J, Yan L, Loureiro RM, Wu I, Fang J, D'Amore PA, et al. Repression of vascular endothelial growth factor expression by the zinc finger transcription factor ZNF24. Cancer Res 2007; 67: 873641.

115 Zhang H, Cui Y, Yu L. Expression of ZNF191 mRNA in ovarian malignant tumors. Acad J Sec Mil Med Univ 2003; 24: 1381-2. Chinese.

116 Liu G, Jiang S, Wang C, Jiang W, Liu Z, Liu C, Saiyin H, et al. Zinc finger transcription factor 191 , directly binding to beta-catenin promoter, promotes cell proliferation of hepatocellular carcinoma; Hepatology 2012; 55: 1830-9.

117 Li J, Chen X, Liu Y, Ding L, Qiu L, Hu Z, et al. The transcriptional repression of platelet-derived growth factor receptor-beta by the zinc finger transcription factor ZNF24. Biochem Biophys Res Commun 2010; 397: 318-22.

118 Zhang J, Cao R, Zhang Y, Jia T, Cao Y, Wahlberg E. Differential roles of PDGFR-alpha and PDGFR-beta in angiogenesis and vessel stability. FASEB J 2009; 23: 153-63.

119 Ostman A. PDGF receptors-mediators of autocrine tumor growth and regulators of tumor vasculature and stroma. Cytokine Growth Factor Rev 2004; 15: 275-86.

120 Jia D, Hasso SM, Chan J, Filingeri D, D’Amore PA, Rice L, et al. Transcriptional repression of VEGF by ZNF24: mechanistic studies and vascular consequences in vivo. Blood 2013; 121: 707-15.

121 Jia D, Huang L, Bischoff J, Moses MA. The endogenous zinc finger transcription factor, ZNF24, modulates the angiogenic potential of human microvascular endothelial cells. FASEB J 2015; 29: 1371-82.

122 Xu L, Begum S, Hearn JD, Hynes RO. GPR56, an atypical G proteincoupled receptor, binds tissue transglutaminase, TG2, and inhibits melanoma tumor growth and metastasis. Proc Natl Acad Sci U S A 2006; 103: 9023-8.

123 Yang L, Chen G, Mohanty S, Scott G, Fazal F, Rahman A, et al. GPR56 regulates VEGF production and angiogenesis during melanoma progression. Cancer Res 2011; 71: 5558-68.

124 Yang L, Xu L. GPR56 in cancer progression: current status and future perspective. Future Oncol 2012; 8: 431-40.

125 Gaudry M, Bregerie O, Andrieu V, El Benna J, Pocidalo MA, Hakim J. Intracellular pool of vascular endothelial growth factor in human neutrophils. Blood 1997; 90: 4153-61.

126 Boesiger J, Tsai M, Maurer M, Yamaguchi M, Brown LF, Claffey KP, et al. Mast cells can secrete vascular permeability factor/vascular endothelial cell growth factor and exhibit enhanced release after immunoglobulin E-dependent upregulation of fc epsilon receptor I expression. J Exp Med 1998; 188: 1135-45.

127 Italiano JE Jr, Richardson JL, Patel-Hett S, Battinelli E, Zaslavsky A, Short $\mathrm{S}$, et al. Angiogenesis is regulated by a novel mechanism: pro- and antiangiogenic proteins are organized into separate platelet alpha granules and differentially released. Blood 2008; 111: $1227-$ 33.

128 Shi GZ, Yuan Y, Jiang GJ, Ge ZJ, Zhou J, Gong DJ, et al. PRAF3 induces apoptosis and inhibits migration and invasion in human esophageal squamous cell carcinoma. BMC Cancer 2012; 12: 97.

129 Chen H, Bai J, Ye J, Liu Z, Chen R, Mao W, et al. JWA as a functional molecule to regulate cancer cells migration via MAPK cascades and F-actin cytoskeleton. Cell Signal 2007; 19: 1315-27.

130 Bai J, Zhang J, Wu J, Shen L, Zeng J, Ding J, et al. JWA regulates melanoma metastasis by integrin alphaVbeta3 signaling. Oncogene 2010; 29: 1227-37.

131 Lu J, Tang Y, Farshidpour M, Cheng Y, Zhang G, Jafarnejad SM, et al. JWA inhibits melanoma angiogenesis by suppressing ILK signaling and is an independent prognostic biomarker for melanoma. Carcinogenesis 2013; 34: 2778-88.

132 Chen Y, Huang Y, Huang Y, Xia X, Zhang J, Zhou Y, et al. JWA suppresses tumor angiogenesis via Sp1-activated matrix metalloproteinase- 2 and its prognostic significance in human gastric cancer. Carcinogenesis 2014; 35: 442-51.

133 Lu J, Tang Y, Cheng Y, Zhang G, Yip A, Martinka M, et al. ING4 regulates JWA in angiogenesis and their prognostic value in melanoma patients. Br J Cancer 2013; 109: 2842-52.

134 Noh YH, Matsuda K, Hong YK, Kunstfeld R, Riccardi L, Koch M, et al. An N-terminal $80 \mathrm{kDa}$ recombinant fragment of human thrombospondin-2 inhibits vascular endothelial growth factor induced endothelial cell migration in vitro and tumor growth and angiogenesis in vivo. J Invest Dermatol 2003; 121: 1536-43.

135 Volpert OV, Zaichuk T, Zhou W, Reiher F, Ferguson TA, Stuart PM, et al. Inducer-stimulated Fas targets activated endothelium for destruction by anti-angiogenic thrombospondin-1 and pigment epithelium-derived factor. Nat Med 2002; 8: 349-57.

136 Ryan DP, Penson RT, Ahmed S, Chabner BA, Lynch TJ Jr. Reality testing in cancer treatment: the phase I trial of endostatin. Oncologist 1999; 4: 501-8.

137 Thomas JP, Arzoomanian RZ, Alberti D, Marnocha R, Lee F, Friedl $A$, et al. Phase I pharmacokinetic and pharmacodynamic study of recombinant human endostatin in patients with advanced solid tumors. J Clin Oncol 2003; 21: 223-31.

138 Rong B, Yang S, Li W, Zhang W, Ming Z. Systematic review and metaanalysis of Endostar (rh-endostatin) combined with chemotherapy versus chemotherapy alone for treating advanced non-small cell lung cancer. World J Surg Oncol 2012; 10: 170.

139 Ge W, Cao DD, Wang HM, Jie FF, Zheng YF, Chen Y. Endostar combined with chemotherapy versus chemotherapy alone for advanced NSCLCs: a meta-analysis. Asian Pac J Cancer Prev 2011; 12: $2705-11$.

140 Westphal JR. Technology evaluation: ABT-510, Abbott. Cur Opin Mol Ther 2004; 6: 451-7.

This work is licensed under the Creative Commons Attribution-NonCommercial-No Derivative Works 3.0 Unported License. To view a copy of this license, visit http://creativecommons.org/licenses/ by-nc-nd/3.0/ 